\title{
Analisis Stabilitas dan Kekuatan Pengait Bak Angkut Kendaraan Multiguna Pedesaan
}

\author{
Alfian Rafi Harsyawina dan I Nyoman Sutantra \\ Departemen Teknik Mesin, Fakultas Teknologi Industri, Institut Teknologi Sepuluh Nopember (ITS) \\ e-mail: tantra@me.its.ac.id
}

\begin{abstract}
Abstrak-Penggunaan material yang lebih ringan tentunya akan membuat berat kendaraan menjadi berkurang yang akan menyebabkan efisiensi energi yang digunakan akan meningkat. Demikian juga pada penelitian pada kendaraan multiguna pedesaan, untuk melanjutkan penelitian terdahulu maka akan diaplikasikan penggunaan material body carbon fiber. Namun dalam perkembangan teknologi otomotif tentunya tidak boleh melupakan keselamatan dari pengemudi dan penumpang dari kendaraan. Oleh sebab itu, perlu dilakukan analisis stabilitas arah belok dan kekuatan bak aagnkut kendaraan multiguna pedesaan dengan penggunaan material body carbon fiber. Analisis stabilitas dilakukan untuk mengetahui perilaku arah belok kendaraan yang terbagi menjadi tiga, yaitu understeer, oversteer, dan netral. Ketiga perilaku kendaraan tersebut dapat diketahui dengan melakukan beberapa analisis seperti analisis slip, skid, dan guling. Hasil dari penelitian ini adalah bahwa kendaraan multiguna pedesaan bermuatan penumpang paling stabil pada layout CG $1(L f=1,46$ dan $L r=1,13)$ atau $56,37 \%$ wheelbase dari depan. Berdasarkan analisa slip, nilai Koefisien understeer menunjukkan bahwa kendaraan lebih stabil saat melintasi sudut kemiringan melintang jalan $5^{\circ}$ dan $10^{\circ}$. Lalu pada kondisi percepatan lurus, pengereman lurus, dan percepatan belok pengait bak angkut masih dalam keadaan aman sehingga mampu menahan beban yang diterima dari bak angkut.
\end{abstract}

Kata Kunci-Understeer, oversteer, slip, skid, Kus.

\section{PENDAHULUAN}

$\mathrm{P}$ ERTUMBUHAN kendaraan bermotor di Indonesia dari tahun ke tahun terus meningkat berdasarkan data dari BPS [1]. Sebagai perguruan tinggi yang memiliki fokus keilmuan di bidang teknologi, ITS bekerja sama dengan Kementrian Perindustrian dan Perdagangan telah mengembangkan kendaraan multiguna pedesaan bertenaga listrik [2]. Penelitian terdahulu mengenai kendaraan multiguna pedesaan sudah dilakukan dengan variasi muatan barang dan alat produksi. Berdasarkan hasil analisa dari kelima belas posisi titik berat pada kendaraan dengan muatan Multi Purpose Thresher, posisi titik berat dengan pusat muatan berada di jarak 1,21 m dari roda depan dan tinggi $0,7118 \mathrm{~m}$ merupakan posisi titik berat yang paling optimal karena memiliki kondisi oversteer yang paling sedikit dan memiliki nilai understeer index positif yang paling rendah dibandingkan posisi titik berat yang lain. [3] Untuk melanjutkan penelitian terdahulu dari kendaraan multiguna pedesaan ini, maka dilakukan pengembangan terhadap material dari kendaraan ini agar tercapai bobot kendaraan yang lebih ringan sehingga lebih meningkatkan efisiensi penggunaan energi. Kendaraan multiguna pedesaan ini harus memiliki tingkat kenyamanan dan keamanan yang tinggi. Faktor yang mempengaruhi tingkat kenyamanan dan keamanan kendaraan adalah perilaku arah belok kendaraan yang meliputi understeer, oversteer, dan netral [4]. Selain itu perlu diperhatikan pula kekuatan dari pengait bak angkut guna menunjang keamanan dari kendaraan. Untuk melengkapi riset mengenai kendaraan multiguna pedesaan ini, maka akan dilakukan penggantian material body bak angkut menjadi carbon fiber. Analisa yang akan dilakukan yaitu analisa skid, analisa slip dan analisa guling.

Tujuan akhir dari penelitian ini adalah pertama untuk mengetahui perilaku arah belok kendaraan dengan variasi kecepatan, sudut belok, dan sudut kemiringan melintang jalan. Kedua adalah untuk mengetahui kecepatan maksimum dari kendaraan. Terakhir penelitian ini bertujuan untuk mengetahui kekuatan dari pengait bak angkut kendaraan pada berbagai kondisi pengereman dan percepatan.

\section{URAIAN PENELITIAN}

Penelitian ini dilakukan dengan beberapa tahap, yaitu melakukan analisa slip, skid, dan guling. Kemudian setelah itu dilakukan analisa gaya - gaya pada pengait bak angkut untuk kemudian digunakan sebagai input simulasi untuk mengetahui tegangan yang diterima oleh pengait. Berikut ini adalah beberapa tahapan dalam melakukan penelitian ini.

\section{A. Analisa Stabilitas Kendaraan \\ 1) Titik Berat Kendaraan}

Titik berat kendaraan sangat berpengaruh terhadap stabilitas kendaraan. Letak tiitk berat kendaraan dapat berpengaruh terhadap perilaku arah belok kendaraan. Di mana semakin titik berat kendaraan berada di depan maka kendaraan cenderung mengalami understeer. Demikian sebaliknya untuk perilaku belok oversteer. Pengukuran titik berat dilakukan dengan menghitung gaya reaksi yang terjadi pada roda depan dan belakang pada kondisi kendaraan benar-benar dalam posisi datar horizontal. Gaya reaksi pada roda depan (Wf) dan gaya reaksi pada roda belakang $(\mathrm{Wr})$ apabila dijumlahkan akan sama dengan berat total dari kendaraan $(\mathrm{W})$. Ilustrasi perhitungan titik berat kendaraan ditampilkan pada Gambar 1. Sebelum terdapat penumpang dan muatan, perhitungan titik berat adalah sebagai berikut.

$\sum M_{B}=0$ (asumsi $(+)$ arah CCW)

$W . l_{f}=W_{r} . L$

$l_{f}=\frac{W_{r} \cdot L}{W}$ 


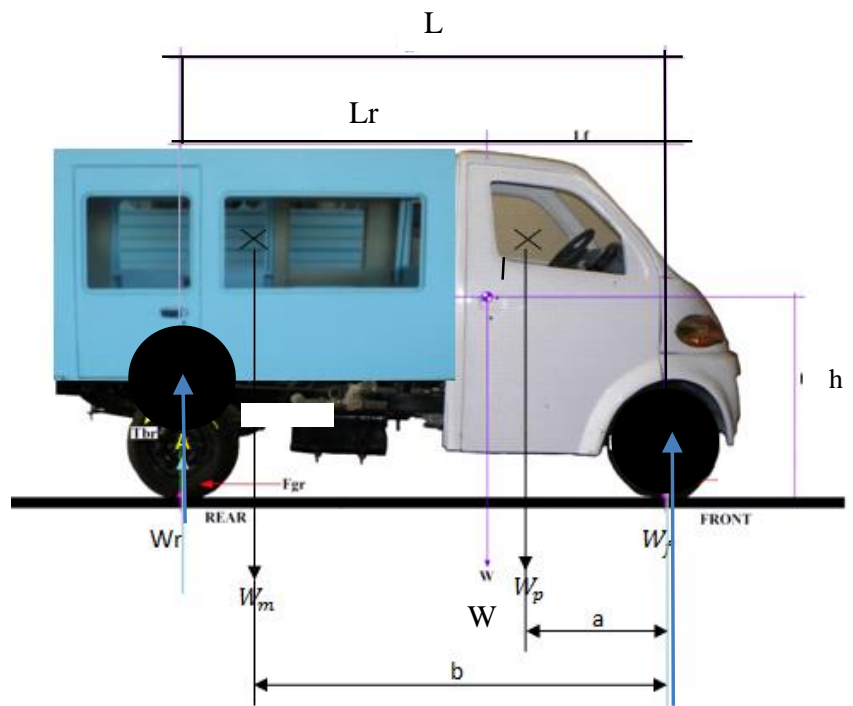

Gambar 1. Free Body diagram kendaraan multiguna pedesaan setelah penambahan muatan dan penumpang

di mana $\mathrm{W}$ adalah berat seluruh kendaraan dan $\mathrm{L}$ adalah wheelbase atau jarak antara roda depan dan belakang.

Sedangkan setelah penambahan bak angkut dan muatan, maka perubahan titik berat kendaraan menjadi

$W_{r} \cdot L=W_{p} \cdot a+W_{k} \cdot l_{f}+W_{m} \cdot b$

$l_{f}^{\prime}=\frac{\sum W_{i} \cdot l_{i}}{\sum W_{i}}$

$l_{f}^{\prime}=\frac{W_{r} \cdot L}{W_{t}}$

di mana $W_{\mathrm{r}}$ adalah berat bagian belakang, $\mathrm{W}_{\mathrm{f}}$ berat bagian depan, $\mathrm{W}_{\mathrm{k}}$ berat kendaraan, $\mathrm{W}_{\mathrm{m}}$ berat muatan, $\mathrm{W}_{\mathrm{t}}$ berat total kendaraan, a adalah jarak titik berat penumpang ke sumbu roda depan, dan $b$ jarak titik berat muatan ke sumbu roda depan.

Posisi tinggi titik berat dapat diketahui dengan menopang roda depan atau roda belakang dengan timbangan dan mendongkrak roda lainnya hingga membentuk sudut $(\theta)$. Setelah mengetahui berat kendaraan di roda depan dan belakang, dengan sudut $(\theta)$ yang diketahui kita dapat menghitung tinggi tiitk berat dari kendaraan.

$h_{r}^{\prime}=\frac{\sum W_{i} \cdot h_{i}}{\sum W_{i}}$

$h_{r}^{\prime}=\frac{\left(W+W_{p}\right) \cdot \sin \theta \cdot h_{r}{ }^{\prime}+W_{m} \cdot \sin \theta \cdot h_{m}}{\left(W+W_{p}\right) \cdot \sin \theta+W_{m} \sin \theta}$

$h_{r}^{\prime}=\frac{\left(W+W_{p}\right) \cdot h_{r}{ }^{\prime}+W_{m} \cdot h_{m}}{W+W_{p}+W_{m}}$

di mana $W_{f \theta}$ adalah berat depan kendaraan saat ditimbang, $h_{p}$ adalah jarak titik berat penumpang dengan sumbu roda, $h_{m}$ adalah jarak titik berat muatan dengan sumbu roda, $\theta$ sudut dongkrak mobil, $r$ adalah jari-jari ban, dan $h_{r}{ }^{\prime}$ adalah tinggi pusat titik berat setelah penambahan berat penumpang dan berat muatan.

\section{2) Analisa Slip}

Analisa slip adalah sebuah metode untuk mengetahui perilaku arah belok kendaraan dengan menghitung sudut slip yang terjadi pada masing - masing ban. Untuk mengetahui sudut slip, maka harus diketahui terlebih dahulu reaksi gaya - gaya yang terjadi pada masing - masing ban. Free Body Diagram reaksi gaya pada roda depan ditunjukkan pada gambar 2. Berikut ini adalah persamaan untuk gaya reaksi ban masing - masing pada roda depan dan belakang.

$$
\begin{aligned}
& F_{x_{2}}=\frac{1}{2}\left[F_{c_{f x} .} \cos \delta_{f}-F_{c_{f y} .} \sin \delta_{f}\right] \\
& F_{y_{2}}=\frac{1}{2}\left[F_{c_{f y} .} \cos \delta_{f}+F_{c_{f x} .} \sin \delta_{f}\right] \\
& F_{x_{1}}=\frac{F_{c r x}}{2}=\frac{L_{f}}{2 . L} F_{c} \sin \beta \\
& F_{y_{1}}=\frac{F_{c r y}}{2}=\frac{L_{f}}{2 . L}\left(F_{c} \cos \theta \cos \beta-\mathrm{W} \sin \theta\right)
\end{aligned}
$$

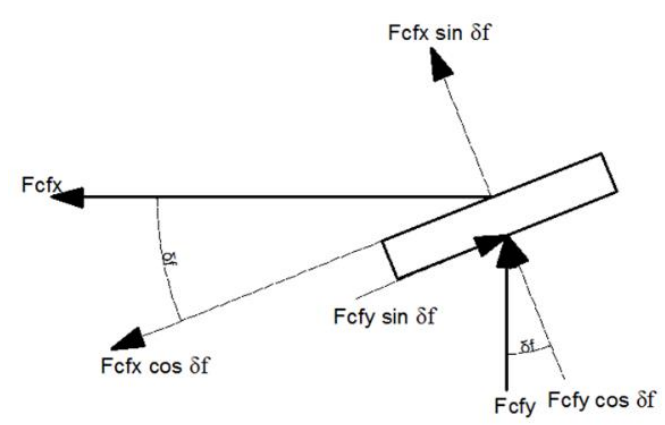

Gambar 2. Free Body Diagram reaksi gaya pada roda depan [4]

Setelah mencari Fx (2an) Fy pada masing-masing roda dan dengan diketahuinya berat roda depan dan berat roda belakang, maka dapat diketahui pula Fz dari masing-masing roda. Untuk mencari nilai $\mathrm{Fz}$ pada roda depan dan belakang dilakukan dengan persamaan berikut.

$$
\begin{aligned}
F_{z_{2}}= & \frac{W_{f}}{2}+\frac{F c_{f} . h}{t} \\
= & \frac{l_{r}}{2 L}\left(W \cos \theta+F_{c} \cos \beta \quad \sin \theta\right)-\frac{l_{r}}{2 L} \\
& \left(\frac{F_{c} \cdot h \cdot \cos \beta \cdot \cos \theta-W \cdot h \cdot \sin \theta}{0.5 \cdot t_{f}}\right)+\frac{F_{c} \cdot h \sin \beta}{2 L} \\
F_{z_{1}}= & \frac{W_{r}}{2}-\frac{F c_{r} h}{t} \\
= & \frac{l_{f}}{2 L}\left(W \cos \theta+F_{c} \cos \beta \sin \theta \quad-\frac{l_{f}}{2 L}\right. \\
& \left(\frac{F_{c} \cdot h \cdot \cos \beta \cdot \cos \theta-W \cdot h \cdot \sin \theta}{0.5 \cdot t_{f}}\right)-\frac{F_{c} \cdot h \sin \beta}{2 L}
\end{aligned}
$$

Setelah mengetahui seluruh gaya pada ban, dapat diketahui nilai sudut slip pada ban dengan persamaan berikut.

$\alpha_{i}=\frac{C_{r p}}{C_{r s}} \cdot \frac{C_{r x}}{C_{r o}}\left[0,087935\left(F_{y \alpha i}\right)^{0,79008}-0,005277\left(F_{z_{i}}\right)\right]$

di mana $\alpha_{i}$ adalah Sudut slip yang terjadi pada setiap ban, $F_{y \alpha i}$ adalah gaya belok lateral yang terjadi pada setiap roda/ban [lb], $F_{z_{i}}$ adalah gaya normal yang terjadi pada setiap roda [lb], $C_{r p}=3,35+5,30(\mathrm{P})-0,0916(\mathrm{P})^{2}, C_{r s}$ $=3,35+5,30\left(\mathrm{P}_{s}\right)-0,0916(\mathrm{P})^{2}, \mathrm{P}$ adalah Tekanan aktual ban kendaraan [Psi], $\mathrm{P}_{\mathrm{s}}$ adalah Tekanan standar ban 
kendaraan $[25 \mathrm{psi}], C_{r x}=\left[\frac{F_{y \alpha i}+0,107927\left(F_{x}\right)}{161,1398}\right]^{\frac{1}{0,47998}}$, dan $C_{r o}=$ $\left[\frac{F_{y \alpha i}}{161,1398}\right]^{\frac{1}{0,47998}}$.

Kemudian setelah mengetahui sudut slip ban, kita dapat mengetahui perilaku arah belok kendaraan dengan nilai Koefisien understeer (Kus). Jika nilai Kus bernilai positif, maka perilaku belok kendaraan adalah understeer dan jika nilai Kus adalah negative maka perilaku belok kendaraan adalah oversteer.

$K_{u s}=\left(\alpha_{f}^{\circ}-\alpha_{r}{ }^{\circ}\right) \frac{R \cdot g}{V^{2}}$

di mana $K_{u s}$ adalah Koefisien understeer, $\alpha_{\mathrm{f}}$ adalah sudut slip roda depan, $\alpha_{\mathrm{r}}$ adalah sudut slip roda belakang, $\mathrm{V}$ adalah kecepatan belok, dan $\mathrm{R}$ adalah radius belok kendaraan.

\section{3) Analisa Skid}

Analisa skid dilakukan untuk mengetahui batas kecepatan kendaraan agar tidak mengalami skid. Persamaan untuk mengetahui batas kecepatan skid roda depan dan belakang adalah sebagai berikut.

$$
\begin{aligned}
& V_{f S}=\sqrt{\frac{R \cdot g \cdot l_{r}\left(\sin \theta+\mu_{m} \cos \theta\right)}{l_{r}\left(\cos \theta-\mu_{m} \sin \theta\right) \cos \beta-\mu \cdot h \sin \beta}} \\
& V_{r s}=\sqrt{\frac{R \cdot g \cdot l_{f}\left(\sin \theta+\mu_{m} \cos \theta\right)}{l_{f}\left(\cos \theta-\mu_{m} \sin \theta\right) \cos \beta+\mu \cdot h \sin \beta}}
\end{aligned}
$$

di mana $V_{f s}$ adalah kecepatan maksimum roda depan $(\mathrm{m} / \mathrm{s})$, $V_{r s}$ adalah kecepatan maksimum roda belakang, $\mathrm{R}$ radius belok jalan $(\mathrm{m}), \mu_{m}$ adalah koefisien gesek melintang, $\theta$ adalah sudut kemiringan melintang $\left(^{\circ}\right), \beta$ adalah sudut side slip $\left(^{\circ}\right)$, h adalah tinggi center of gravity kendaraan $(\mathrm{m})$.

\section{4) Analisa Guling}

Analisa guling adalah metode untuk mengetahui kecepatan kritis kendaraan akan mengalami roda terangkat atau guling. Ketika kendaraan mengalami kondisi guling tentu akan berbahaya bagi penumpang. Analisa dilakukan dengan persamaan berikut ini.

$$
\begin{aligned}
& V_{f_{g}}=\sqrt{\frac{R \cdot g \cdot l_{r} \cdot\left(\cos \theta+h \cdot \sin \theta / 0.5 \cdot t_{f}\right)}{l_{r} \cdot h \cdot \cos \beta \cdot \cos \theta / 0.5 \cdot t_{f}-\left(l_{r} \cos \beta \cdot \sin \theta+h \cdot \sin \beta\right)}} . \\
& V_{r g}=\sqrt{\frac{R \cdot g \cdot l_{f} \cdot\left(\cos \theta+h \cdot \sin \theta / 0.5 \cdot t_{r}\right)}{l_{f} \cdot h \cdot \cos \beta \cdot \cos \theta / 0.5 \cdot t_{r}-\left(-h \cdot \sin \beta+l_{f} \cos \beta \cdot \sin \theta\right)}}
\end{aligned}
$$

\section{B. Analisa Kekuatan Pengait Bak Angkut}

Analisa Kekuatan Pengait Bak Angkut dilakukan untuk mengetahuui nilai tegangan dan safety factor dari pengait ketika mendapatkan gaya dari bak angkut ketika kendaraan mengalami pengereman lurus dan belok serta percepatan lurus dan belok. Free Body Diagram gaya yang diterima pengait pada kondisi kendaraan mengalami pengereman belok ditunjukkan pada gambar 3. Untuk mengetahui gaya gaya pada pengait ketika mengalami pengereman belok adalah sebagai berikut.

$$
\begin{aligned}
& F x=\frac{(m \cdot a+F c \sin \beta-\mu k \cdot W)}{4} \\
& F y_{2}=\frac{\left(\frac{L r}{L} \cdot F c \cos \beta-\mu k \cdot W\right)}{2}
\end{aligned}
$$

$$
F z=\left(\left(\frac{m \cdot a \cdot h}{L}-\frac{W \cdot L f}{L}\right)+\left(\frac{L f}{L} \cdot F c \cos \beta \cdot \frac{h}{b}-\frac{W}{2}\right)\right) / 2
$$

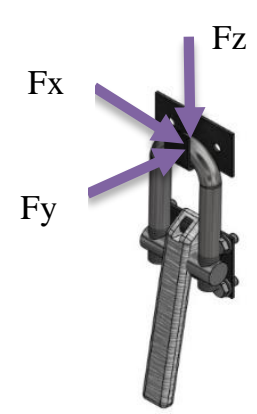

(a)

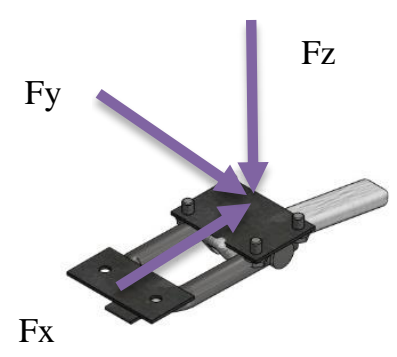

(b)
Gambar 3. Free Body Diagram reaksi gaya pada pengait saat pengereman belok: (a) model pengait samping (b) model pengait atas

\section{HASIL DAN PEMBAHASAN}

\section{A. Analisa Kestabilan Arah Belok Kendaraan}

Pada analisa kestabilan arah belok kendaraan ini pertama dilakukan pada kendaraan bermuatan penumpang. Analisa dilakukan dengan muatan maksimal yaitu 6 orang penumpang. Kemudian penulis membuat 3 variasi layout kursi penumpang sehingga terjadi perbedaan di letak titik berat dari kendaraan. Variasi layout kursi penumpang ditunjukkan pada tabel 1. Dari ketiga variasi tersebut dipilih layout CG 1 karena memiliki kondisi oversteer yang paling sedikit dan memiliki nilai Kus positif paling kecil. Setelah mengetahui layout penumpang terbaik, maka pad layout tersebut dilakukanlah berbagai analisa yaitu analisa slip, skid, guling, dan kekuatan pengait bak angkut.

Grafik Koefisien understeer vs sudut belok ditampilkan pada gambar 4. Berdasarkan analisa slip, diketahui bahwa kendaraan lebih banyak mengalami oversteer ketika berbelok. Kemudian trendline dari grafik adalah selalu menurun dengan bertambahnya nilai dari sudut belok. Semakin tinggi kecepatan belok juga menyebabkan nilai dari Kus semakin berkurang. Hal ini disebabkan semakin bertambahnya kecepatan dan sudut belok maka besarnya sudut slip juga akan bertambah. Namun ketika kendaraan melintasi permukaan jalan dengan sudut kemiringan melintang jalan yang lebih besar, kestabilan kendaraan lebih baik karena nilai sudut slip lebih kecil pada sudut kemiringan $5^{\circ}$.

Setelah mengetahui perilaku arah belok kendaraan, selanjutnya kita dapat mengetahui batas kecepatan maksimum kendaraan berdasarkan analisa skid dan guling. Grafik batas kecepatan skid vs sudut belok kendaraan multiguna pedesaan ditunjukkan pada gambar 5. Sementara grafik batas kecepatan guling vs sudut belok ditunjukkan pada gambar 6.

Berdasarkan grafik tersebut, dapat kita ketahui bahwa batas kecepatan skid akan semakin tinggi dengan bertambahnya sudut kemiringan melintang jalan. Hal ini disebabkan adanya gaya lateral tambahan yang arahnya melawan gaya sentrifugal yang dihasilkan kendaraan ketika 
berbelok. Berdasarkan gambar 4.6 batas kecepatan kendaraan ketika berbelok pada sudut belok $5^{\circ}$ adalah 62 $\mathrm{km} / \mathrm{jam}$. Secara keseluruhan kendaraan akan cenderung mengalami kondisi oversteer karena $V_{f s}>V_{r s}$.

Tabel 1.

Variasi Layout Penumpang Kendaraan Multiguna Pedesaan

\begin{tabular}{ccc}
\hline \hline \multirow{2}{*}{ Variasi } & Jarak ke roda depan $(\mathrm{m})$ & Jarak ke roda belakang $(\mathrm{m})$ \\
\hline$C G 1$ & 1,46 & 1,13 \\
$C G 2$ & 1,57 & 1,02 \\
$C G 3$ & 1,68 & 0,91 \\
\hline \hline
\end{tabular}

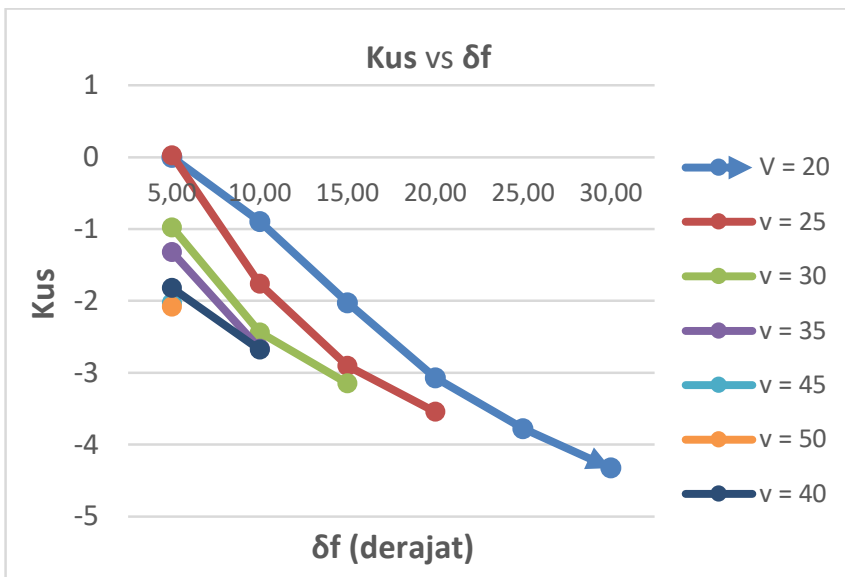

Gambar 4. Grafik Korfisien understeer vs sudut belok kendaraan bermuatan penumpang

\section{Batas kecepatan skid vs $\delta f$}

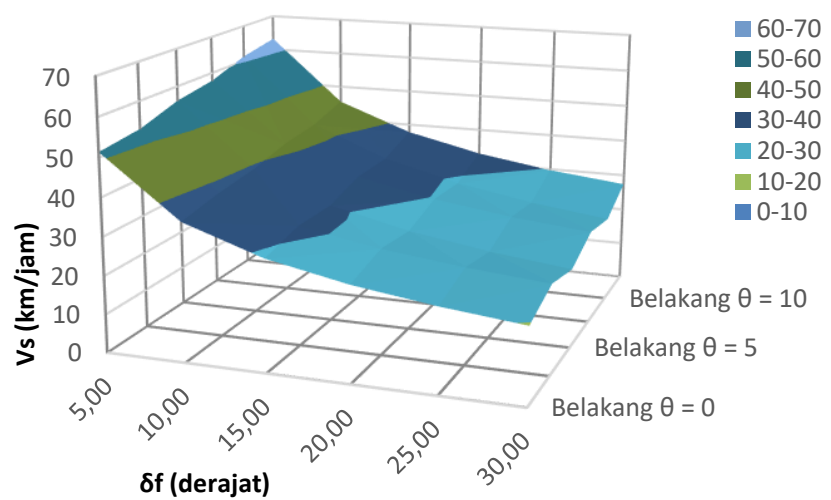

Gambar 5. Grafik batas kecepatan skid (Vs) vs sudut belok kendaraan multiguna pedesaan dengan muatan penumpang posisi CG 1 pada keadaan aspal kering

Kendaraan dalam kondisi kritis akan terguling Karena terangkatnya salah satu atau kedua ban terluar ketika berbelok. Hal ini disebabkan oleh besarnya gaya normal yang terjadi pada ban kendaraan tidak dapat menahan berat kendaraan, dengan kata lain gaya normal yang terjadi bernilai nol atau negatif. Pada grafik juga dapat disimpulkan bahwa trendline grafik mengalami penurunan pada setiap penambahan sudut belok kendaraan. Hal itu menunjukkan bahwa kecenderungan kendaraan akan mengalami guling akan meningkat seiring dengan bertambahnya sudut belok kendaraan. Dari grafik juga dapat dilihat bahwa batas kecepatan guling akan meningkat seiring dengan bertambahnya sudut kemiringan melintang jalan. Hal ini disebabkan karena adanya gaya tambahan menuju pusat bumi yang dihasilkan ketika kendaraan melintas di sudut kemiringan melintang jalan lebih dari nol derajat.

\section{Batas Kecepatan Guling vs $\delta f$}

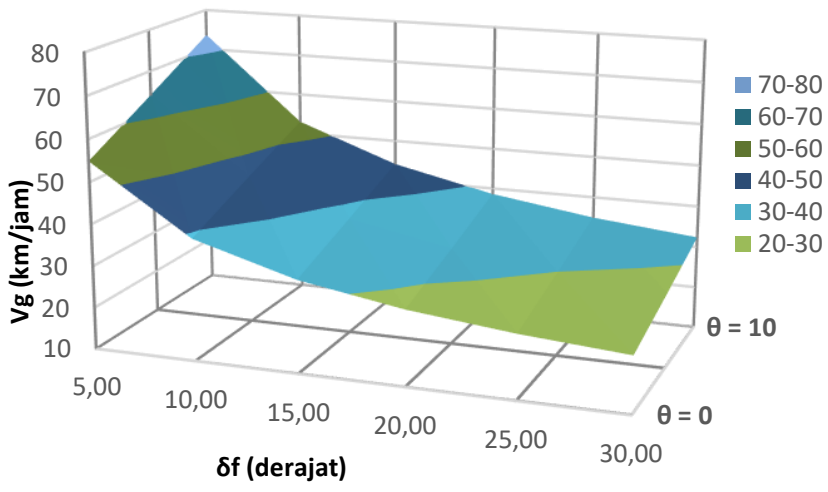

Gambar 6. Grafik batas kecepatan guling roda belakang (Vrg) vs sudut belok kendaraan multiguna pedesaan dengan muatan penumpang posisi $\mathrm{CG}$

Untuk membuktikan bahwa kestabilan kendaraan akan lebih baik ketika melintasi jalan dengan sudut kemiringan melintang jalan yang lebih besar maka akan ditunjukkan grafik Kus vs sudut belok pada sduut kemiringan melintang jalan 5 dan $10^{\circ}$ pada gambar 8 .

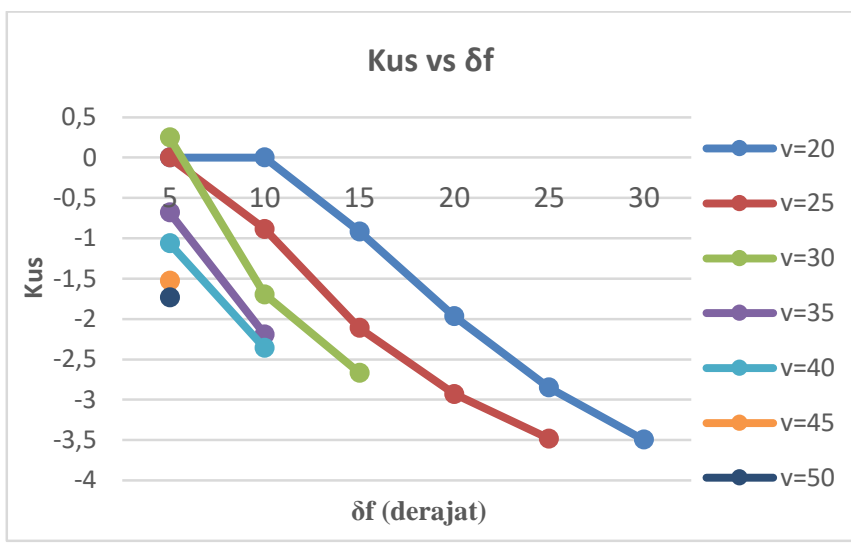

Gambar 7. Grafik Koefisien Understeer vs Sudut Belok belok kendaraan multiguna pedesaan bermuatan penumpang pada posisi CG 1 pada aspal kering dengan sudut kemiringan melintang jalan $\theta=5^{\circ}$

Berdasarkan gambar 8, dapat diketahui bahwa nilai Kus lebih mendekati nol pada gambar 8 daripada gambar 7. Pada gambar 8 kendaraan lebih banyak mengalami kondisi netral daripada gambar 7. Selain itu pada gambar 7 nilai Kus yang dihasilkan lebih kecil daripada gambar 8. Hal ini menunjukkan bahwa kendaraan lebih mengalami oversteer pada sudut kemiringan yang lebih kecil.

\section{B. Analisa Kekuatan Pengait Bak Angkut Kendaraan}

Hasil dari gaya reaksi pada pengait ditunjukkan pada tabel 3. Gaya yang terjadi pada pengait bak angkut kendaraan akan dianalisa dalam 4 keadaan, yaitu saat pengereman dan percepatan lurus serta pengereman dan percepatan belok. Analisis akan dilakukan hanya pada salah satu pengait yang menerima gaya paling besar pada masing - masing kondisi kendaraan. Pada analisa ini, pengait bak 
angkut kendaraan dibagi menjadi 3 bagian yaitu pengait, plat pengait, dan baut pengait.

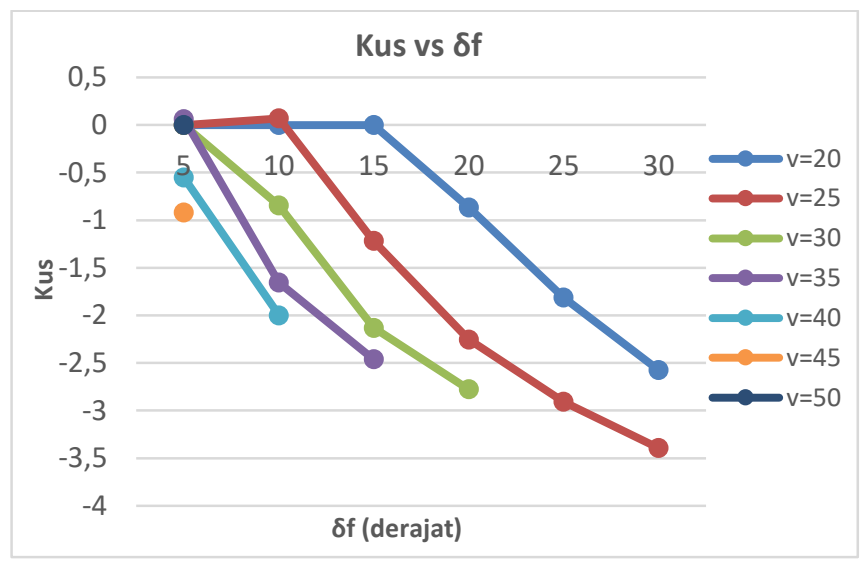

Gambar 8. Grafik Koefisien Understeer vs Sudut Belok belok kendaraan multiguna pedesaan bermuatan penumpang pada posisi CG 1 pada aspal kering dengan sudut kemiringan melintang jalan $\theta=10^{\circ}$.

Tegangan maksimal yang diterima pengait adalah 104,1 MPa dengan nilai safety factor adalah 2,4 pada model pengait atas saat pengereman lurus. Sedangkan tegangan maksimal yang diterima oleh pengait saat percepatan lurus adalah $64,85 \mathrm{MPa}$ dengan nilai safety factor 3,85. Kemudian pada kondisi percepatan belok tegangan yang diterima oleh pengait adalah 120,3 MPa dengan nilai safety factor 2,07. Terakhir pada kondisi pengereman belok tegangan yang diterima oleh pengait adalah 415,82 $\mathrm{MPa}$ dengan safety factor 0,6. Pada kondisi belok pengait menerima tegangan yang lebih besar daripada saat kondisi lurus dikarenakan pengait menerima gaya tambahan yaitu gaya sentrifugal yang dihasilkan kendaraan saat belok. Berdasarkan analisa kekuatan pengait diketahui bahwa pengait mengalami kegagalan saat kendaraan dalam kondisi pengereman belok dengan kecepatan belok $40 \mathrm{~km} / \mathrm{jam}$ dan sudut belok $10^{\circ}$.

\section{KESIMPULAN}

Kesimpulan yang dapat ditarik dari penelitian ini adalah stabilitas kendaraan multiguna pedesaan terbaik pada layout penumpang CG 1 atau $56,73 \%$ dari panjang wheelbase. Kemudian berdasarkan analisa skid dan guling diketahui bahwa kendaraan akan lebih sulit mengalami skid saat melintasi permukaan jalan dengan sudut kemiringan melintang yang lebih besar. Hal ini disebabkan adanya gaya lateral yang melawan gaya sentrifugal kendaraan saat berbelok. Berdasarkan hasil dari analisa slip, kendaraan akan lebih stabil saat berbelok jika sudut kemiringan melintang jalan yang dilewati semakin besar karena nilai Koefisien understeer indeks (Kus) yang dihasilkan cenderung mendekati nol. Kendaraan bermuatan penumpang memiliki trendline grafik yang sama pada setiap kecepatan, yaitu nilai Kus yang semakin menurun dengan bertambahnya $\delta$ f. Berdasarkan semua analisis yang dilakukan dapat diketahui bahwa kendaraan cenderung mengalami oversteer saat bermuatan penumpang. Kemudian berdasarkan analisa kekuatan pengait yang telah dilakukan, didapatkan data bahwa pengait memiliki nilai safety factor kurang dari 1 pada kondisi pengereman belok, sehingga pengait mengalami kegagalan. Kegagalan tersebut terutama terjadi pada komponen plat pengait.

\section{DAFTAR PUSTAKA}

[1] Kantor Kepolisian Republik Indonesia, "Perkembangan Jumlah Kendaraan Bermotor Menurut Jenis Tahun 1987 - 2013,” 2013.

[2] A. S. Pramono, Rancang Bangun Kendaraan Multiguna Pedesaan. Surabaya, 2014

[3] M. N. Azhar, "Analisa Perilaku Arah Kendaraan Produksi Multiguna Pedesaan Dengan Variasi Muatan, Kecepatan, Sudut Belok, dan Sudut Kemiringan Melintang Jalan,” ITS, 2016.

[4] dan B. S. Sutantra, I Nyoman, Teknologi Otomotif, Edisi Kedua. Surabaya: Guna Widya, 2010 